\title{
AARD EN KARAKTER VAN SURINAAMSCHE LIEDEREN
}

\author{
DOOR \\ JHR. L. C. VAN PANHUYS
}

Men zal zich wellicht herinneren, dat ik in het Februari-nummer 1935 van dit tijdschrift den musicoloog Mr. J. Kunst, die een standaardwerk schreef over de toonkunst op Java, een uitnemend kenner noemde van de Nederlandsche volksmuziek. Ik deed dit op gezag van den hoogleeraar dr. E. von Hornbostel, met wien ik over de liederenverzameling van Frater Fulgentius en van den Heer J. P. J. Berkenveld heb gecorrespondeerd, en ik verzocht daarna op raad van prof. v. H. aan Mr. K., of hij in die verzameling oud-Nederlandsche volksliederen kon terugvinden. Sedert kwam mij een lijst van geschriften over folklore en dialecten in Nederland in handen, en mede daaruit vernam ik, dat Mr. K. in 1916 een (te Uithoorn uitgekomen) boek met platen uitgaf over Terschellinger volksleven, gebruiken, feesten en liederen (met melodie), dat een soort nationaal boek voor de Terschellingers is geworden en nu is uitverkocht, en in het volgende jaar bij Wolters te Groningen het eerste deeltje van Noord-Nederlandsche volksliederen en -dansen, uit den volksmond opgeteekend en bewerkt voor zang en piano, met silhouetten van Henriëtte Bolkema; er is al een 2dedruk van en er zijn drie deeltjes van verschenen. Het vierde is in bewerking.

Mr. Kunst schrijft mij, dat hij over de liederenverzameling F. en B. slechts enkele aanteekeningen heeft gemaakt, en ik zal die hieronder vermelden. Maar tevens heb ik Frater Fulgentius, die met verlof hier te lande vertoeft, met de opmerkingen in kennis gesteld en $\mathrm{Zijn}$ Eerwaarde heeft mij het genoegen gedaan, de drie liedjes, die Mr. K. bespreekt, van cijfer- in notenschrift over te brengen, opdat ze in dit tijdschrift zouden kunnen worden opgenomen.

$\mathrm{Nu}$ volgen de opmerkingen. De melodie van lied 1 toont duidelijk den invloed van het Gregoriaansch. Ik voeg hierbij de vertaling van de negerengelsche woorden. 

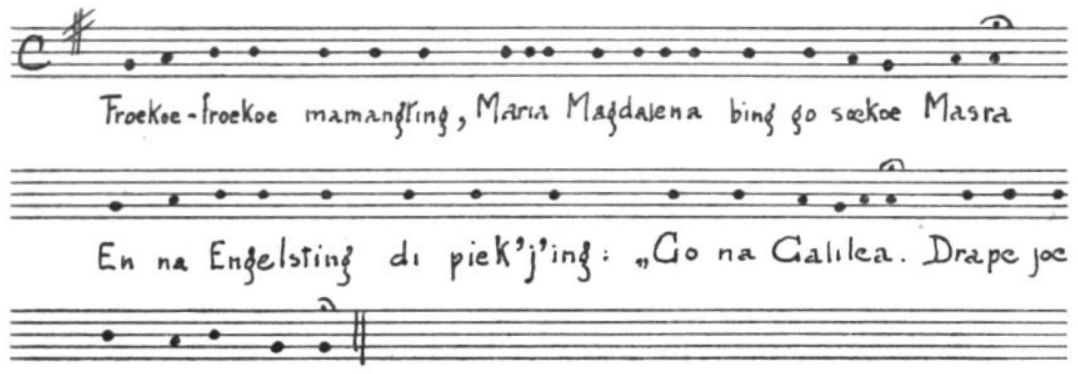

so Fienie Masra

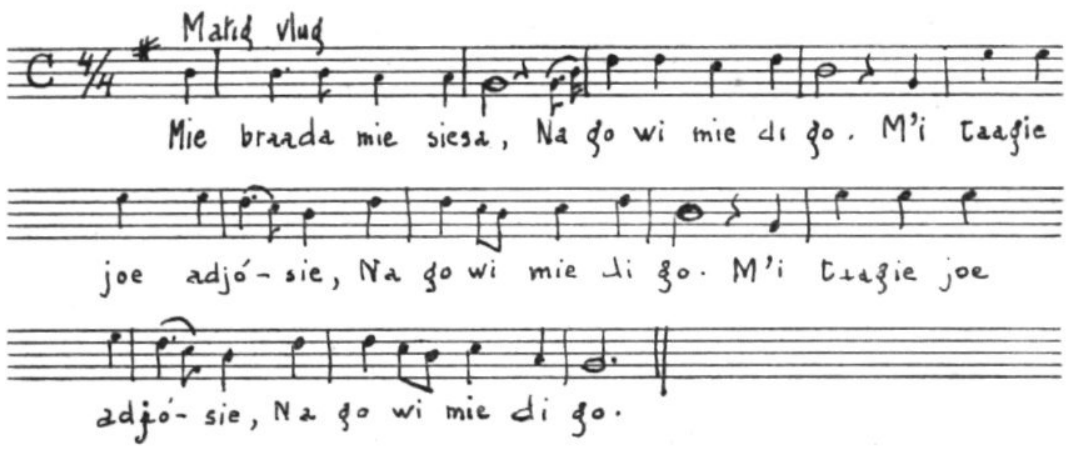

Refrein

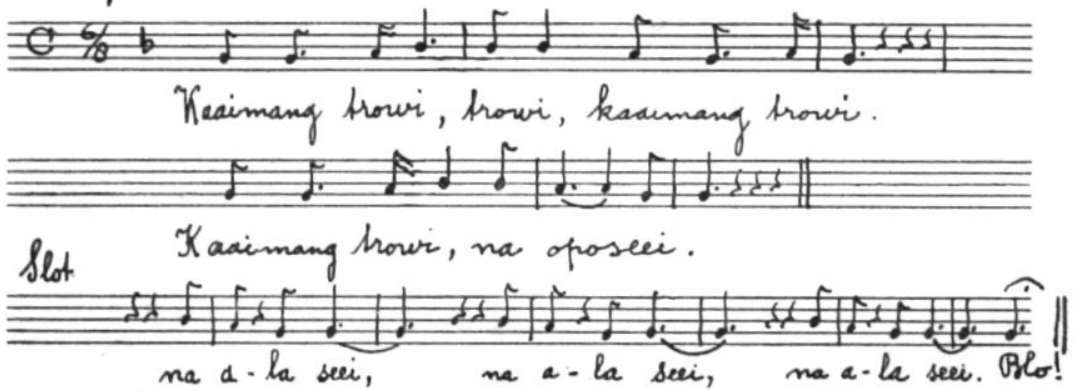

Heel vroeg in den morgen

Is Maria den Heer gaan zoeken

En een engel stond daar

die Haar antwoordde

Ga naar Galilea.

Daar zult Gij den Heer vinden. 
De melodie van het tweede lied ${ }^{1}$ ) is identiek met de bekende melodie van „De twee koningskinderen”, zooals deze, zegt Mr. K., in het Noorden van ons land, b.v.op Terschelling, gezongen wordt; de oorsprong van die melodie is Duitsch. De vertaling van den tekst van het eerste en van het mij later door Frater F. gezonden tweede couplet houdt slechts het volgende in:

$$
\begin{aligned}
& \text { Mijn broeder en mijn zuster } \\
& \text { Ik ga nu van } U \text { heen } \\
& \text { Ik zeg U vaarwel, } \\
& \text { Ik zeg } U \text { adieu. }
\end{aligned}
$$

en verder:

Adieu mijn zuster Ik ga naar mijn Heiland. $(2 \times)$

Frater Fulgentius schrijft mij nog, dat dit lied in Suriname in sterfhuizen (dus bij de plechtigheid van "dede hoso", neem ik aan) gezongen wordt.

Ik vraag mij af, hoe het mogelijk is, dat van de legende van de twee koningskinderen alleen het slot in Suriname aanwezig is. Zou de negerbevolking in het beschaafde gedeelte het geheele lied in vroeger tijd door blanken hebben hooren zingen; zou zij zich van den treurigen inhoud rekenschap hebben gegeven; het begin en het midden hebben vergeten, maar ervan bewust zijn gebleven, dat het sobere overblijfsel van het slot (wanneer - wat uit de woorden van den Surinaamschen tekst niet blijkt, - de prinses met den verdronken koningszoon in zee springt) een afscheid voor goed beteekende? Ik geef hier ter vergelijking het slot van het lied, zooals dat onder den titel: „Van twee Koningskinderen, Horae Belgicae, Pars II" voorkomt in den 8sten druk, Amsterdam 1911, van het Nederlandsch Volksliederenboek door D. de Lange, Jhr. Mr. J. C. M. van Riemsdijk en dr. G. Kalff, uitgave van de Maatschappij tot Nut van 't algemeen, blz. 101. Het slot in het tweede boek van het Liederboek van Groot-Nederland door F. C. Coers, Amsterdam, 1898, is nagenoeg gelijkluidend (wat de woorden aangaat; de melodie van beide liederen is verschillend):

1) Ik voor mij hoor daarin die van: ,Wir hatten gebauet ein stattliches Haus", A. von Binzer, 1819, Thüringsche Volksweise, Erk's Deutscher Liederschatz, Leipzig, Band I. blz. 212. 
13. Si nam hem in haer armen Si spronk er mee in de see: „Adieu, mijn vader en moeder! „Van uw leven siet ghi mi niet meer!

14. „Adieu mijn vader en moeder! „Mijn vriendekens alle ghelijc, „Adieu, mijn suster en broeder! „Ic vaerder nae 't hemelrijc".

De Duitsche tekst is weer soberder en luidt in de Unterrichtlieder für eine Singstimme mit klavierbegleitung, herausgegeben von Max Friedlaender, Leipzig 1898, C. F. Peters, aldus:

Sie schwang sich um ihren Mantel und sprang wohl in die See:

„Gut Nacht, mein Vater und Mutter, „ihr seht mich nimmermeh!" $(2 \times)$

Van het derde lied schrijft Mr. K., dat het evengoed Ambonneesch zou kunnen zijn en dus van Portugeesche afkomst zal wezen. Verhalen met liedjes er door heen, zooals elders in de collectie voorkomen, zijn naar mr. K. opmerkt ook typisch Javaansch (het z.g.n. dongèng).

Ik geef hier de vertaling van het derde lied, waarvan Frater F. mij het vervolg in het negerengelsch en eenige bijzonderheden heeft medegedeeld. Het is een roeierslied. De stuurman begint te reciteeren: „Iedereen is even bang voor den kaaiman. Daarom (om die reden)”. Dan zingen de roeiers het refrein: „Kaaiman, draai om, zwem naar den overkant”. Achtereenvolgens reciteert de stuurman, steeds heftiger, dat zijn vader, dat zijn moeder, dat zijn dikke broertje en zuster, allen even bang zijn, evenveel vrees hebben voor den kaaiman, om telkens door de roeiers met het refrein te worden beantwoord. $\mathrm{Nu}$ roept de stuurman uit: „Mi Ga” (afkorting en eenigszins een bemanteling van de uitdrukking: Mijn God nog toe), en verder: „de kaaiman springt in de boot". Daarna roept hij, dat al zijn kameraden, de roeiers, voor den kaaiman geducht benauwd zijn, om in zijn slot-recitatief te vragen: „En hoe staat het met den bootsman zelf?” Het antwoord, dat de stuurman zelf geeft is: „De stuurman is voor den kaaiman in 't geheel niet benauwd". Het slotrefrein van de roeiers gelast nu den kaaiman om alle kanten uit te gaan. Het 
slotwoord of de slotklank: „Blo” beteekent, dat de kaaiman wordt weggeblazen (in overdrachtelijken zin); tegelijk wordt ook het verhaal en het lied met die klank uitgeblazen (zooals in Hollandsche kinderverhalen de olifant doet).

$$
* *
$$

Terwijl nu op blz. 316 van het Februari-nummer van dit tijdschrift de stellige uitspraak van prof. van Hornbostel is weergegeven, dat de liederen in de verzameling voor de vergelijkende muziekwetenschap zonder belang zijn, bedenke men, dat liederen en tekst in zekeren zin een geheel vormen. Reeds de taal, het negerengelsch, verleent aan de liederen een bijzonder cachet, maar ook de wijze van voordracht drukt er een eigenaardige stempel op. Bovendien geven de liederen, zij het dan dat ze van andere volken zijn overgenomen, de psyche, den aard van de Surinaamsche kreolenbevolking toch zeker voor een belangrijk deel weder.

Als omlijsting van hunnen arbeid, en vermoedelijk om te doen uitkomen, hoe Surinaamsche liederen niet alleen door de melodie, maar ook door tekst, rythme, voordracht, tempo, voor de volkenkunde van belang kunnen zijn, hebben de drie verzamelaars aan hunne opmerkingen aanhalingen uit tal van werken toe gevoegd. Ik vermoed, dat Frater F. het grootste deel zelf heeft gevonden. Doch hoe dit zij, ik acht het van belang, dat iemand die de Surinaamsche muziek aan een diepgaand en veelomvattend onderzoek wil onderwerpen, profiteeren kan van den voorarbeid, die door het opzoeken van de citaten reeds door de heeren Frater Fulgentius, Berkenveld en Van Vliet is verricht. Het komt mij bovendien daarom wenschelijk voor van die aanhalingen een overzicht te geven, omdat ze ook voor den beschaafden leek niet zoo gemakkelijk te vinden zijn en toch zulk een belangrijke bijdrage kunnen vormen voor algemeene ontwikkeling. In Suriname waar men toch altijd leeft in een betrekkelijk isolement, worde men te eerder in de gelegenheid gesteld het merkwaardige in eigen, onmiddellijke omgeving te toetsen aan hetgeen in de geschiedenis voorafging of bij andere volken weer op overeenkomstige wijze wordt aangetroffen.

Ik vang dus aan met een overzicht van de citaten, die aan de collectie F. F. en Hr. B. zijn toegevoegd. De vertaling is van mij.

J. Schönhärl. Regierungslehrer in Lome. Volkskundliches aus Togo. Dresden, 1909.

Blz. 155. De rythme is in het bijzonder bij de muziek van de 
Ewe-stammen zeer eigenaardig en samengesteld. Onze ooren kunnen er aanvankelijk geen bepaalde maat in terugvinden. Bij langdurig en vaak luisteren onderscheidt men meest een tweedeelige maat. Van andere liederen zonder trombegeleiding is het rythme zoo veranderlijk, dat een maatverdeeling niet mogelijk is.

Frater F. meent, dat dit laatste het zingend spreken is, dat bij de kreoolsche stads- en plantagebevolking zoo veelvuldig voorkomt. (Het woord „plantagebevolking” is eigenlijk niet juist; ik bedoel de kreolen op plantages en gronden in de onder rechtstreeksch bestuur staande gedeelten van Suriname). Meest geschiedt dat zingend spreken in Suriname op psalmtoon, op twee noten; op „banja-wijs” zegt het volk.

Blz. 156. Zonder metronoom is het tempo niet nauwkeurig te bepalen. Niettegenstaande het snelle vroolijke tempo is voor ons de geest, het karakter van de dansliederen eerder klagend en weemoedig dan vroolijk. Gezangen voor dooden hebben meest een snel tempo, maar de slottonen worden lang uitgehaald.

Blz. 162. Het programma biedt op een dansavond weinig afwisseling. Een en hetzelfde vers wordt soms uren lang herhaald. De voorzanger intoneert en de anderen zingen het refrein, dan wel het geheele lied opnieuw, ad infinitum. Is de oude tekst lang genoeg gezongen, dan bedenkt de voorzanger vaak een nieuwe strophe, die het koor met groot genoegen dadelijk overneemt. Er worden onbeduidende feiten bezongen of wel men gaat tot een spotlied over, waarin aan de zangers vijandig gezinde personen worden beschimpt. Voorzanger en koor vullen elkaar aan, zoeken elkander in de keuze van scherpe uitdrukkingen te overtreffen. Het vurige tempo en 't eigenaardige rythme trekken aan en houden de aandacht levendig, al ontbreken aan de liederen poëzie en een rijke melodie.

Frater F. merkt hierbij op, dat volgens Stedman ook de slaven in Suriname zich zoodanig door zang en dans voelden aangetrokken, dat zij van Zaterdagavond tot Maandagmorgen in een stuk door, dus „ad infinitum”, aan den gang bleven.

Blz. 163. De Ewe-ers zijn als alle natuurmenschen muzikaal; ze houden van muziek. De meesten hebben een goed gehoor en kunnen muziek onthouden, al zijn, jammer genoeg, hunne stemmen ruw en ongeschoold en van geringen omvang, terwijl zij, ook bij de jongeren, laag zijn. Toch zingt alles zoo luid mogelijk mede.

Frater F. acht dat in bovenstaande aanhalingen vele aanwijzingen voorkomen voor het schoolzangonderwijs aan kreolen en negerjeugd in Suriname. 
Blz. 187. In Lome zijn twee elkaar vijandige partijen, de „Gekleede Lieden" of Awumé, zoo genoemd omdat zij in Europeesche dracht zijn, en de „Weegschaal-Menschen” (Sikeli), die vroeger een weegschaal met geld en kostbaarheden bij hunne dansen tentoonstelden, om daarmede de Awumé te hoonen. Want de schaal met geld (die de Sikeli beduidde) was altijd zwaarder dan de schaal met kostbaarheden, die de andere partij voorstelde. De oude Doe's in Suriname, met hun strijdende partijen zijn door Pater Rikke beschreven in zijn boek Ma Kankantree.

Dr. A. Mansfeld. Vier Jahre unter den Grossflussnegern Kameruns. Berlin 1908.

Blz. 133. Men zingt en dankt hier bij iedere gelegenheid .Als een familielid overlijdt, wanneer een kind geboren wordt, wanneer de zon om twaalf uur brandt, als het flink regent, bij het roeien (of pagaaien?), bij den veldarbeid. Zelfs een wegens oproer ter dood veroordeeld hoofd schreed zingend met danspassen naar de galg toe.

J. Fräszle. S. C. J. Mijn Oerwoudnegers in hun doen en denken. Sittard. 1925.

Blz. 146. Nauwelijks op marsch zet mijn volk den beurtzang in. Zij roepen aan de Wadangs hun laatste groeten toe: aan de mannen, kinderen, honden, kippen, boomen, straten, hutten, potten, het eten, het vuur, enz. Dan wordt de gong aangeroepen, het woud, de dieren, de vogels, wolken, winden, de zon; alles moet door de lucht; de lieden van Mokaris boodschappen, dat de dokter van God naar hen onderweg is, om hun zielen te komen genezen. „Maakt je dorp schoon, reinigt de hutten, komt uit het bosch, keert terug van de jacht, verzamelt de kinderen, haalt ook water en voedsel voor hen en voor ons allemaal!"

„Hoor je het, Matoendoeloe, heer van Mokaria? En gij, onze broeder, Emilio Boela, katechist van de kinderen. Je vader komt en wij komen met hem".

J. Fräszle. Negerpsyche. Freiburg i. B. 1926.

Blz. 18. De Europeaan zwijgt wanneer hij arbeidt. In Afrika is het omgekeerd. Daar trekt men zingend naar het werk. De kracht van het gezang toont hoe ernstig men bezig is; hoe luider het gezang, hoe fermer daad. Het gezang geeft het rythme voor den arbeid aan. Wanneer mijn arbeiders zwegen, moest ik vlug naar hen toe, want dan zaten zij op den grond niets te doen. 
Baron Albert von Sack, zoo voegt Frater Fulgentius hier bij, spreekt over stadsslavinnen, die zingend dweilen en met de dweil de maat wuiven; op een reis tot ver boven de Jodensavanna zongen de roeiers steeds, zegt hij. Eigenaardig acht Fr. F. het, dat geen enkele Hollandsche beschrijving van oud-Suriname over plantage-arbeidsliederen van de veldslaven spreekt.

Ik heb tijdens mijn verblijf in Suriname (Febr. 1892-1Aug. 1896) wel vernomen, dat wanneer op de koffieplantages koffieboonen werden gestampt, er door het volk lustig op de maat bij werd gezongen, en de opzichters ook gaarne hadden dat er bij dien arbeid gezongen werd, omdat er dan beter en ijveriger werd gewerkt.

Dr. Fr. Kossmann. Nederlandsch versrythme. 's Gravenhage 1922.

Blz. 204. Reeds in die meest primaire menschelijke uitingen, die men als de beginselen der dichtkunst pleegt voor te stellen staan beide vormen van rythmiek naast elkander. Het bootsmanslied, dat in gerekte tonen, slechts melodisch varieerend, zuiver de maatslagen der riemen volgt, is in aanleg isochroon. Voegt zich bij dit alleen de slagen tellende rythme een levendiger figuratie, een verhalende, spottende of ondeugende tekst, dan zal, evenals in de variaties der muziek, een isometrisch rythme ontstaan, dat vrijer speelt tusschen en over de vaste hoofdslagen en in ongetelde hoeveelheden van tonen metra vormt uit dezelfde maatduren, die eerst eenheid en "chronos" waren. Zoo vindt men het bij beschaafde en "wilde" volkeren in tallooze voorbeelden, in rijmpjes, roei-, ruiter-, stamp-, dans-, hei- en wiegeliedjes. Vaak ligt een overgang van den eenen tot den anderen rythme-vorm ten grondslag aan het verschil van indruk tusschen lied en refrein; de eene helft is druk babbelend, de andere afgemeten en vast.

J. Brummelkamp. Sociale Geographie van Afrika. II. Groningen 1930.

Blz. 75. Ook zingen de negers heel graag, en veel. Schweinfurth zegt: hun zingen heeft veel van een recitatief, dat lijkt op een afwisseling van hondengejank en koeiengeloei, aldus weer te geven: ff $><$ ff. Dat is echter overdreven. Xandt vermeldt, dat op de negerscholen in D.-O.-Afrika de prestaties van de leerlingen in den zang het best zijn. $\mathrm{Zij}$ zingen er heel aardig Duitsche volksliedjes, in het Kiswaheli. vertaald. Evenals hun muziek zijn hun 
liederen een eindelooze herhaling van eenzelfde strophe begeleid door trom en handgeklap, of het is een recitatief. De melodie is vaag, moeilijk in onze toonschalen weer te geven; kaoetsjoekmelodie zegt Pechuel Loesche. Harmonie is er ook weinig, al bezitten zij eenig accoordgevoel. Meestal zetten de stemmen op verschillende hoogten in en bewegen zich dan parallel. Ondanks tegenspraak op dit punt, is rhythmus ook niet het fundament van hun muziek en zang, doch treedt alleen op bij het roeien en trommelen. Bij het dansen stemmen melodie, handenklappen, trommelen en beenbeweging, rythmisch niet overeen.

De woorden der liederen hebben meestal niets om het lijf.

Naar mijn inzien volkomen terecht, keurt Frater Fulgentius de bovenstaande compilatie van den Heer Brummelkamp, een samenvatting van oppervlakkigheden van geleerden met beroemde namen, maar die op dit speciaal gebied hunne onkunde toonen, in scherpe bewoordingen af. Het lijkt wel, merkt Fr. F. op, of de heer B. zijn lezers op die wijze denkt te kunnen klaarstoomen voor een examen. Hoofdaktecandidaten zouden zoo doende, schijnt de Heer B. te denken, nu ineens een eigen oordeel hebben. De bewondering van oude missionarissen voor het negerlied, en van geleerden, die op dit gebied bijzondere studies maakten en fraaie verzamelingen aanlegden, schijnt voor den heer B. niet te hebben geteld.

Frater Fulgentius wijst er bovendien op - en nu denk ik aan een kortgeleden door mij in het tijdschrift gemaakte opmerking, dat De West Indische Gids een levende aanvulling vormt van de Encyclopaedie van Nederlandsch West Indië, dat in die encyclopaedie op blz. 498, 2de kolom, een oordeel is uitgesproken, dat niet strookt met de waardeering, die missionarissen hebben betoond voor onvergetelijken negerzang en dichtkunst. Wij hebben ons te ontworstelen, zoo is de indruk van steller dezes, aan den invloed van grove materialistische opvattingen en uitingen van oppervlakkige waarnemers uit een voorbijgegaan tijdperk. Maar frater F. maakt ons opmerkzaam op nog een andere fout op de genoemde bladzijde van de encyclopaedie. Aldaar wordt namelijk gezegd dat Bonaparte in zijn „Les habitants de Surinam”, pag. 187, den tekst geeft van een groote verzameling negerliedjes. Maar t.a.p. is die groote verzameling niet te vinden. Bonaparte geeft hoogstens twee negerengelsche dichtstukjes die niet tot de folklore behooren, maar van 'n kleinkunstenaar (Europeaan?) afkomstig zijn. Waarschijnlijk een „Aria siengie" uit 'n Zangboekje der Hernhutters. Dat er een 
„grand nombre de ces genres existent dans la colonie" is een bewering van een spoedreiziger.

Baron A. van Sack. Reize naar Surinamen I. Haarlem 1821.

Blz. 152. Een bijzonderheid uit dit korte citaat, n.l. een mededeeling over het „makreelen-lied”, heb ik opgenomen in mijn artikel Folklore in Suriname, deel XVI, blz. 22 bovenaan van dit tijdschrift.

Mr. H. C. Focke. De Surinaamsche Negermuzyk. Tijdschrift West-Indië, 2de deel, Haarlem, 1858, blz. 93-107, met vijftien liedjes, o.a. tien banja-gezangen, in notenschrift.

Op den inhoud van dit belangrijke artikel, dat gemakkelijk in iedere groote bibliotheek kan worden geraadpleegd, gaan wij niet verder in. Deze muziek, zegt Mr. F. op blz. 99, is wellicht, evenals de Negerengelsche taal, door Afrikaansche ooren en stemmen op Portugeeschen oorsprong opgetrokken. Frater F. zegt, dat de noot op blz. 101, over Hartsinck's bewering, blz. 908 van zijn „Beschrijving van Guiana”, over onkieschheid van de negers in houding en gebaren bij hunne dansen, welke bewering Mr. F. als onjuist verklaart, door Hartsinck ontleend is aan Père Labat's „Nieuwe reize naar de fransche eilanden van Amerika”, Amsterdam 1725, waaruit ook Fermin putte, doch dat Labat ze wederom ontleende aan Rochefort ,,Histoire naturelle et morale des Iles Antilles de l'Amérique", Rotterdam, 1658.

Dr. Bern. Zuure. Afrikaansche vulpenkrassen. 5de serie, Boxel, 1923.

Blz. 132. Deze aanhaling bevat een beschrijving van een marsch in Afrika, gedurende welke de missionaris hoort, hoe langzamerhand door de dragers een lied wordt ingezet, en hoe dit ontstaat. Wat de melodie betreft, drong zich bij dr. $Z$. vooral de vergelijking op met het Gregoriaansch, waartoe ook wel de vrijere maatindeelingen bijdroegen.

Dr. Z. critiseert prof. Weule, wanneer deze in zijn „Negerleben in Ost-Afrika”, Leipzig 1938, en in „Wissenschaftliche Ergebnisze”, in „Mitteilungen aus den Deutschen Schutzgebieten, mit Erganzungsheft", I, Berlin 1908, den inhoud van de negerliederen zinloos en belachelijk noemt. Zoo schijnt het den oppervlakkigen toehoorder en zoo is het wel eens, maar lang niet altijd, zegt dr. $Z$., die verder het bewijs aanwezig acht, dat de tekst vaste verzen heeft, die met den muzikalen vorm tegelijk worden overgeleverd. 't Is juist die samenhang tusschen zang en tekst, die het moeilijk 
maakt sommige melodieën, die daar toch bijzonder voor geëigend zouden zijn, in de kerk te gebruiken, omdat ze de Christenen te gemakkelijk aan den daarvan in hunne gedachte niet te scheiden zin doet denken.

Daar prof. von Hornbostel, die een wereldnaam heeft op het gebied van de kennis van Afrikaansche muziek, mij nadrukkelijk waarschuwt tegen het werk van A. Friedental over kreolen-muziek in Amerika, wil ik daaruit geen aanhalingen doen. Het is mij opgevallen, dat Friedental het kleine niet eert en b.v. het eiland Curaçao „winzig" noemt, hoewel zijn land zich destijds voor het bezit van het zeker niet grootere Helgoland wel veel moeite heeft gegeven. Opmerkingen van Frater Fulgentius naar aanleiding van het bewuste geschrift geef ik echter gaarne hier weer. De Kondré-siengi, speciaal de schimp- en schertsliedjes, zijn talloos en tevens zijn zij eendagsvlinders. Echte minneliederen acht Fr. F. zeldzaam in Suriname. Als men daar de liefde en de schoone sexe nobel wil bezingen, geschiedt het op Hollandsche minneliederen. Obsceene scherts- en schimpliederen van de straat, welke op lobbi-siengie partijen worden gezongen, zijn er in overvloed. Het meerstemmig zingen is bij de Surinaamsche Kreolen zeer geliefd. In kerk en school wordt er steeds meerstemmig onder de melodie gebromd. Pogingen op letterkundig gebied in het Negerengelsch vindt men alleen in de oude kerk-zangbundels, en ook een weinig onder de leden der Begi's (Godsdienstige zangpartijen ontstaan uit gebedsbijeenkomsten der huiselijke liturgie van de Herrnhutters). Na de abolitie in 1808 zijn, zoo meent Fr. F. vele slaven uit de Spaansche, Fransche en Portugeesche koloniën in Suriname ingevoerd, en allicht brachten zij melodieën mede. In de katholieke kolonies van Spanje, Frankrijk en Portugal werd de slaaf meer in de Europeesche cultuur opgenomen dan in de Engelsche en Hollandsche, alwaar de slaven buiten de landskerk en buiten de taalgemeenschap werden gehouden; daardoor, wil Fr. F. klaarblijkelijk concludeeren, was er in de laatgenoemde kolonies minder ontleening van Europeesche muziek door de gekleurden. Muziek en dans acht Fr. F. ook voor de armsten onder de armen een onschuldig vermaak. Plebs en obsceniteit zijn niet twee onafscheidelijke begrippen.

Van de door den heer van Vliet gegeven aanhalingen gaf ik een opsomming aan het eind van de bespreking van zijn liederenverzameling. $\mathrm{Na}$ het bovenstaande uitvoerige overzicht van de citaten van frater Fulgentius zal ik nagaan in hoever daardoor een overzicht van de aanhalingen van den heer van Vliet over- 
bodig zal zijn geworden, en in hoever ze voor het weergeven van aard en karakter van Surinaamsche liederen belangrijk zijn.

Ik besluit nu met de vermelding van een feit, waarop Mr. Kunst mij opmerkzaam maakte, n.l. dat in den feestbundel, te Weenen gedrukt, die in 1928 aan Pater P. W. Schmidt, Directeur van het Volkenkundig Museum van het Lateraan te Rome werd aangeboden en die 76 studiën bevat op het gebied van de taalwetenschap, de volkenkunde, de godsdienstwetenschap, en de voorgeschiedenis (ik kondigde het groot formaat boekwerk van XXIX en 977 bladzijden aan in de Nieuwe Rotterdamsche courant van 13 Mei van dat jaar, ochtendblad A) een artikel voorkomt van den meergenoemden hoogleeraar E. M. von Hornbostel, getiteld: Die Masznorm als kulturgeschichtliches Forschungsmittel, dat geen onderzoeker van primitieve muziek en -muziekinstrumenten over het hoofd mag zien, en dat aantoont hoe de studie van wat met primitieve muziek samenhangt groote verrassingen kan opleveren. Prof. v. H. bespreekt in dat artikel o.m. de gelijkwaardigheid van absolute toonhoogte en maat-norm, en bewijst o.a. de volgende stelling: „Die Vergleichung der auf Instrumenten mit fester Abstimmung gemessenen Schwingungszahlen erscheint als ein besonders zuverlässiges Hilfsmittel für die kulturhistorische Forschung". 